\title{
Contribuição ao conhecimento dos Clytini neotropicais (Coleoptera, Cerambycidae, Cerambycinae)
}

\author{
Maria Helena M. Galileo ${ }^{1,3}$ \& Ubirajara R. Martins 2,3 $^{2,3}$
}

\begin{abstract}
${ }^{1}$ Museu de Ciências Naturais, Fundação Zoobotânica do Rio Grande do Sul. Caixa Postal 1188, 90001-970 Porto Alegre-RS, Brasil. ${ }^{2}$ Museu de Zoologia, Universidade de São Paulo. Caixa Postal 42494, 04218-970 São Paulo-SP, Brasil.

${ }^{3}$ Pesquisador do CNPq.
\end{abstract}

\begin{abstract}
Contributions to the knowledge of the Neotropical Clytini (Coleoptera, Cerambycidae, Cerambycinae). The following new taxa are described and figured: from Colombia (Magdalena): Cetimaju, gen. nov., type species $C$. abare sp. nov. and Tanyochraethes minca sp. nov.; from Brazil: M. ycoca sp. nov. (Amazonas) and Neoclytus turuna sp. nov. (Amazonas, Pará); from Ecuador: N. anama sp. nov. (Loja); from Peru: N. potiuna sp. nov. (Cuzco); from Peru and Bolívia: N. pinima (Ica, Chaparé).
\end{abstract}

KEYWORDS. Mecometopus; Neoclytus; neotropical; new taxa; Tanyochraethes.

RESUMO. Contribuição ao conhecimento dos Clytini neotropicais (Coleoptera, Cerambycidae, Cerambycinae). São descritos e figurados os novos táxons da Colômbia (Magdalena): Cetimaju, gen. nov., espécie-tipo C. abare sp. nov. e Tanyochraethes minca sp. nov.; do Brasil: M. ycoca sp. nov. (Amazonas) e Neoclytus turuna sp. nov. (Amazonas, Pará); do Equador: N. anama sp. nov. (Loja); do Peru: N. potiuna sp. nov. (Cuzco); do Peru e da Bolívia: N. pinima (Ica, Chaparé)

PALAVRAS-CHAVE. Mecometopus; Neoclytus; neotropical; novos táxons; Tanyochraethes.

A inclusão de espécies em Neoclytus Thomson, 1860 e em Mecometopus Thomson, 1860 é feita por caracteres pouco discriminantes e com inúmeras situações intermediárias. Bates (1870) publicou: "Lacordaire unites this genus (Mecometopus) with Neoclytus, but it seems to me to form a distinct and very natural group, distinguished from Neoclytus by the very much shorter and less robust hind legs, which are due proportions to the anterior and middle pair. The muzzle is in almost all the species longer and narrower than in Neoclytus".

O mesmo autor, em 1880: 55, acrescentou sobre Mecometopus: "To the slender form of hind legs, especially the femora, and the elongated and subvertical forehead, are added a distinct style of coloration and markings, and a more circunscribed and compact distribution”. Após Bates, nenhum outro autor cuidou de Mecometopus.

As espécies incluídas atualmente, tanto em Mecometopus como em Neoclytus, necessitam de revisão. Analisando os caracteres adotados por Bates, verifica-se que o comprimento dos metafêmures é muito variável. Se em algumas espécies (M. polygenus Thomson, 1860, espécie-tipo de Mecometopus), os ápices dos metafêmures ultrapassam ligeiramente as pontas dos élitros, em M. aesopus (Chevrolat, 1860) as sobrepassam muito. Os metafêmures são acentuadamente clavados em Mecometopus tumulifer Aurivillius, 1908 ao passo que em $M$. flavius Bates, 1870 são sublineares. O mesmo pode ser dito do comprimento da fronte e do padrão de colorido que são bem diversificados nos dois gêneros.

Descreveremos em Mecometopus as espécies que têm metafêmures sublineares e em Neoclytus aquelas que apresentam metafêmures clavados.

O gênero Tanyochraethes Chemsak \& Linsley, 1965 reúne sete espécies próprias dos Estados Unidos e México além de T. ochrozona (Bates, 1885) registrada para a Guatemala, Honduras e Costa Rica (Monné, 2005). Agora detectamos mais uma espécie procedente da Colômbia. Também será proposto um gênero novo de Clytini por apresentar peculiaridades diferenciais dos demais gêneros da tribo.

As siglas utilizadas no texto correspondem às instituições: ACMS, American Coleoptera Museum, San Antonio (= Coleção J. Wappes); CMNH, Carnegie Museum of Natural History, Pittsburgh; FSCA, Florida State Collection of Arthropoda, Gainesville; MCNZ, Museu de Ciências Naturais, Fundação Zoobotânica do Rio Grande do Sul, Porto Alegre; MNKM, Museo de Historia Natural Noel Kempff Mercado, Santa Cruz; MPEG, Museu Paraense Emílio Goeldi, Belém; MZSP, Museu de Zoologia, Universidade de São Paulo, São Paulo.

\section{Cetimaju gen. nov.}

Etimologia. Tupi, cetimã = perna; ju = espinho, alusivo à armadura dos metafêmures.

Espécie-tipo, Cetimaju abare sp. nov.

Fronte sem carena. Tubérculos anteníferos próximos, distância entre eles menor que aquela entre os lobos oculares inferiores na fronte. Antenas com nove artículos, ultrapassam 
a base dos élitros, antenômero III tão longo quanto o escapo, antenômeros V-IX engrossados, IX com ápice pontiagudo. Protórax mais largo anteriormente do que na base; com lados arredondados. Pronoto densamente pontuado, com pubescência esparsa e uniforme.

Élitros com os lados paralelos e extremidades com espinho externo. Mesofêmures pedunculados e clavados; ápices com dois espinhos curtos, o externo ligeiramente mais longo. Metafêmures sublineares, extremidades com espinho interno curto e espinho externo muito longo. Metatarsômero I mais longo que o comprimento dos artículos II a $\mathrm{V}$ reunidos.

Discussão. O novo gênero caracteriza-se pelo conjunto de caracteres: tubérculos anteníferos próximos entre si; antenas com nove artículos; antenômero IX acuminado; protórax mais largo anteriormente do que na base; ápice dos élitros com espinho externo projetado; ponta dos metafêmures com espinho externo muito alongado. Cetimaju gen. nov. difere de Mecometopus e Neoclytus pelo grande desenvolvimento dos espinhos femorais, pelas antenas com 9 artículos e pelo antenômero IX acuminado.

\section{Cetimaju abare sp. nov.} (Fig. 1)

Etimologia. Tupi, abaré = amigo. .

Cabeça e protórax castanho-avermelhados revestidos por pubescência amarelada, longa, uniforme e moderadamente densa. Antenas alaranjadas na base e gradualmente mais castanho-avermelhadas para o ápice.

Élitros vermelho-acastanhados; em cada um, faixas de pubescência amarelada e longa: (1) dorsal, oblíqua em sentido descendente da sutura para a margem, no sexto anterior; (2) em forma de "V" da sutura à margem com o ramo sutural bem mais longo do que o marginal; (3) transversal, contínua da margem à sutura, no terço apical. Pernas avermelhadas. Face ventral com pubescência esbranquiçada nos mesepimeros, ápice dos metepisternos, lados posteriores do metasterno e margem apical dos urosternitos I e II.

Dimensões mm, holótipo fêmea. Comprimento total, 4,8; comprimento do protórax, 1,1; largura anterior do protórax, 1,0; largura da base do protórax, 0,8 ; comprimento do élitro, 3,$2 ;$ largura umeral, 1,0 .

Material-tipo. Holótipo fêmea, Colômbia, Magdalena: vizinhança de Santa Marta, (50m), II.1957, Steinh col. (MZSP).

\section{Mecometopus ycoca sp. nov.}

(Fig. 2)

Etimologia. Tupi. Yçoca = bicho da madeira .

Cabeça avermelhada. Lobos oculares inferiores mais curtos do que as genas. Antenas com 10 artículos, atingem a base dos élitros; segmentos I a IV alaranjados e V-X enegrecidos e engrossados. Protórax avermelhado, revestido por pubescência fina e curta entre os pontos. Pronoto convexo com fileira central de tubérculos esparsos. Escutelo coberto por pubescência amarelada densa.

Élitros castanho-escuros, com faixas e manchas de pubescência amarelada, cada um com: (1) faixa transversal, estreita, na declividade basal dos élitros; (2) faixa oblíqua em sentido descendente da sutura para a margem sem atingi-las e situada no terço anterior; (3) mancha central, triangular, fundida com a sutura na metade anterior; (4) faixa transversal contínua desde quase a margem até a sutura, no terço posterior; (5) extremidades inteiramente cobertas. Extremidades elitrais obliquamente truncadas com espículo no ângulo marginal. Pernas castanho-avermelhadas; as metatíbias pouco mais claras na metade basal. Mesepimero, metepisterno, lados do metasterno e urosternitos I-IV com pubescência amarelada, densa.

Dimensões mm, macho. Comprimento total, 6,5-7,7; comprimento do protórax, 1,8-2,2; maior largura do protórax, 1,9-2,2; comprimento do élitro, 4,2-4,9; largura umeral, 1,7-2,2.

Material-tipo. Holótipo e dois parátipos machos procedentes do Brasil, Amazonas: Manaus (BR-174, km 64), 20.VIII.1984, M. Hrabovsky col. (holótipo MZSP, 1 parátipo FSCA; 1 parátipo MCNZ).

Discussão. As seguintes espécies de Mecometopus possuem faixa de pubescência amarelada, estreita e transversal, na declividade basal dos élitros: M. nubicollis Zajciw, 1964, M. rhinotragoides Thomson, 1860 e M. rubefactus Bates, 1870. Mecometopus ycoca sp. nov. distingue-se de M. nubicollis e M. rubefactus pela ausência de pilosidade densa e amarelada aos lados da base do protórax e de $M$. rhinotragoides pelo padrão de colorido dos élitros. Em M. rhinotragoides os élitros têm, na metade posterior, larga faixa preta entre as manchas anteriores e apicais de pubescência amarelada.

\section{Mecometopus miri sp. nov.}

(Fig. 3)

Etimologia. Tupi, miri $=$ pequeno, alusivo ao tamanho diminuto.

Pequenas dimensões. Tegumento castanho-escuro com antenas e pernas mais avermelhadas; coxas, processo prosternal, mesosterno e metasterno, alaranjados. Lobos oculares inferiores mais longos que as genas. Fronte com pequena carena longitudinal no centro. Antenas com oito artículos; artículo apical mais longo do que o III. Pronoto convexo, sem faixas claras, com elevação centro-longitudinal discreta; superfície densamente pontuada.

Élitros com faixas e áreas de tegumento castanho-claro revestidas por pubescência esbranquiçada, esparsa e pouco contrastante: (1) faixa oblíqua em sentido descendente da sutura para a margem no terço basal; (2) mancha triangular, central, pouco afastada da mancha oblíqua, fundida com a sutura, na metade anterior; (3) terço apical inteiramente. Extremidades elitrais obliquamente truncadas com espinho 

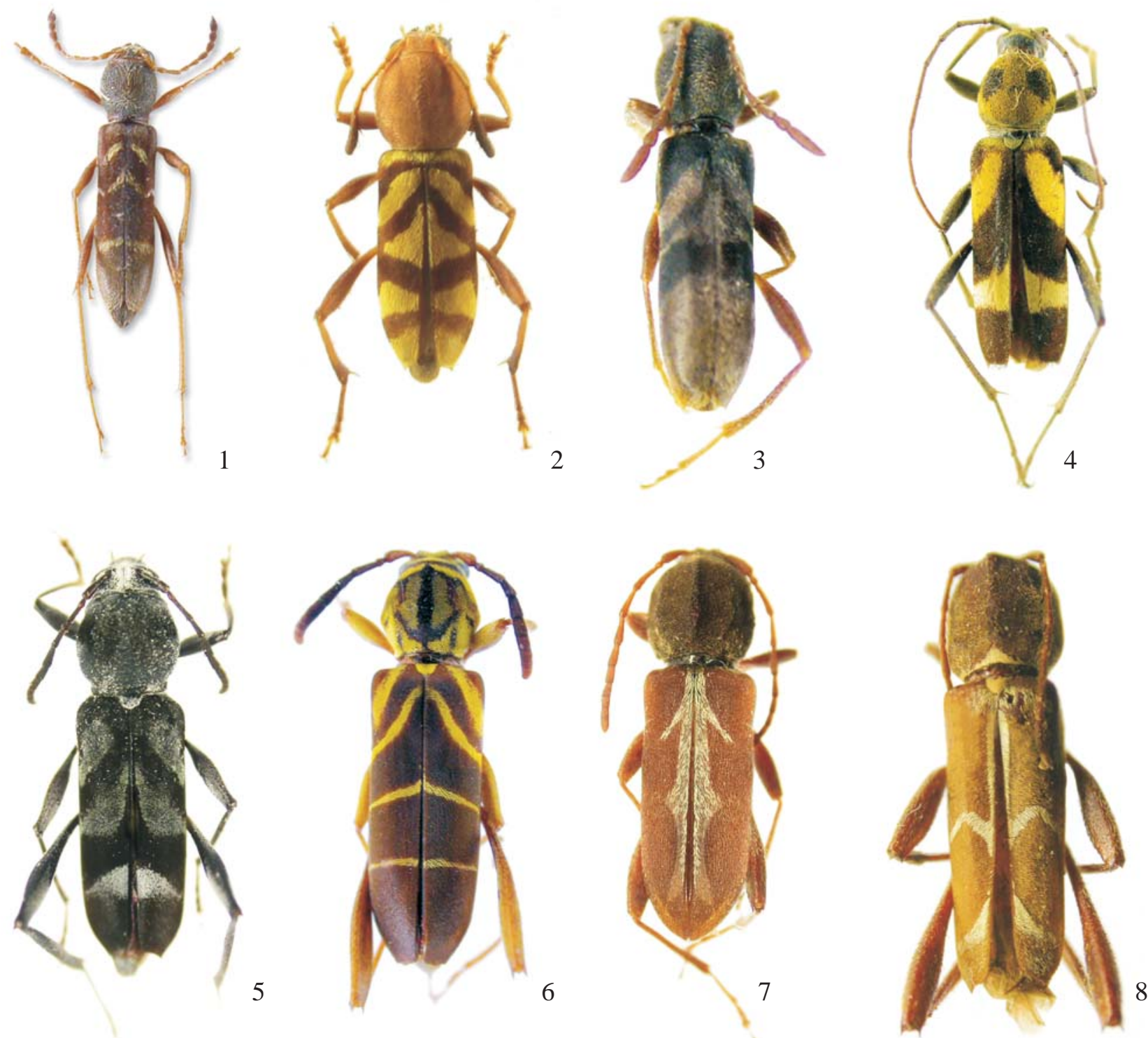

Figs. 1-8. 1-4. Habitus. 1, Cetimaju abare sp. nov., holótipo fêmea, comprimento, 4,8 mm; 2, Mecometopus ycoca sp. nov., holótipo macho, comprimento, 6,7 mm; 3, Mecometopus miri sp. nov., holótipo macho, comprimento, 4,8 mm; 4, Tanyochraetes minca sp. nov., holótipo macho, comprimento, 12,9 mm; 5-8. Habitus. 5, Neoclytus turuna sp. nov., holótipo fêmea, comprimento, 12,7 mm; 6, Neoclytus pinima sp. nov., holótipo fêmea , comprimento, 11,7mm; 7, Neoclytus potiuna sp. nov., holótipo fêmea, comprimento, 13,3 mm; 8, Neoclytus anama sp. nov., holótipo macho, comprimento, 12,5mm. Fotos: E. Moyses.

curto externo. Meso- e metafêmures com abas apicais apenas projetadas. Mesepisterno, base e ápice do metasterno e orla apical do urosternito I com pubescência esbranquiçada, grossa.

Dimensões mm, macho. Comprimento total, 4,8; comprimento do protórax, 1,2; maior largura do protórax, 1,1; comprimento do élitro, 3,3; largura umeral, 1,1.

Material-tipo. Holótipo macho, Bolívia, Santa Cruz, Achira (4$5 \mathrm{~km} \mathrm{~N}$, road to Amboro), 12-13.X.2000, Wappes \& Dozier col. (MNKM).
Discussão. Pelas pequenas dimensões, Mecometopus miri sp. nov. assemelha-se a M. bolivianus Belon, 1899, que também apresenta antenas com oito artículos e profêmures com espinho no ápice externo. Difere pela presença de carena e ausência de faixas longitudinais de pubescência amarelada, contrastantes, na fronte; pelo pronoto sem faixas de pubescência amarelada; pelo padrão de colorido dos élitros e da face ventral do corpo. M. bolivianus não tem carena na fronte; o pronoto tem faixas transversais de pubescência amarelada; a face ventral, além de pubescência nos mesmos escleritos de $M$. miri, tem pubescência amarelada nos metepisternos e na borda apical dos urosternitos I e II. 


\section{Tanyochraethes minca sp. nov.} (Fig. 4)

Etimologia. O epíteto refere-se à localidade-tipo.

Cabeça, antenas, protórax, pernas e face ventral, pretos. Élitros mais acastanhados. Cabeça revestida por pubescência branco-amarelada. Lobos oculares inferiores mais longos que as genas. Lobos oculares superiores atingem internamente $o$ nível dos tubérculos anteníferos; distância entre lobos igual ao triplo da largura de um lobo. Antenas filiformes, com onze artículos, atingem o meio dos élitros. Pronoto convexo; nos machos, revestido por pubescência amarelada, menos em duas áreas circulares ântero-laterais; nas fêmeas, pubescência amarelada junto às orlas anterior e basal; a área central largamente preta.

Cada élitro com duas faixas de pubescência densa, amarelada: (1) faixa oblíqua, em sentido descendente da sutura para a margem, prolongada até o terço anterior e que não atinge a sutura ou a margem; (2) faixa transversal no terço apical que avança um pouco anteriormente junto da sutura. Extremidades elitrais truncadas com espículos externo e interno. Ápices dos metafêmures atingem a borda basal do urosternito V. Abas apicais dos meso- e metafêmures arredondadas. Face ventral inteiramente revestida por pubescência esbranquiçada menos os urosternitos III-V.

Dimensões $\mathrm{mm}$, respectivamente macho/fêmea. Comprimento total, 12,4-12,9/12,0; comprimento do protórax, 2,6-2,7/2,5; maior largura do protórax, 2,8-3,0/2,8; comprimento do élitro, 8,5-8,7/8,4; largura umeral, 3,3-3,6/3,2.

Material-tipo. Holótipo macho, Colômbia, Magdalena: Minca (2000 pés), VI. 1926, CMNH Acc. 1999 (CMNH). Parátipo macho e parátipo fêmea com os mesmos dados do holótipo (MZSP, CMNH).

Discussão. Tanyochraethes minca sp. nov. pelo padrão de colorido dos élitros assemelha-se a T. ochrozona (Bates, 1885); difere pela pubescência amarelada do pronoto com áreas pretas; pela faixa de pubescência amarelada na metade anterior dos élitros, oblíqua em sentido descendente da sutura para a margem sem atingi-las; pela região anteapical dos élitros sem pubescência amarelada. Em T. ochrozona a pubescência amarelada reveste todo o disco central do pronoto; a faixa de pubescência amarelada na metade anterior dos élitros é transversal e toca a sutura e a margem e a região anteapical dos élitros é revestida por pubescência amarelada.

\section{Neoclytus turuna sp. nov.} (Fig. 5)

Etimologia. Tupi, turuna $=$ preto grande.

Tegumento preto. Fronte coberta por pubescência branca prolongada até o occipício e atrás dos olhos. Antenas com onze artículos. Antenômero III tão longo quanto o escapo. Antenômeros V-XI levemente engrossados. Pronoto (macho) sem faixas de pubescência e com grânulos pouco projetados ao longo do disco; pronoto (fêmea) com grânulos menos projetados, pouco evidentes. Escutelo revestido por pubescência branca, densa.

Élitros com áreas cobertas por pubescência esbranquiçada e pouco contrastante; cada um com: (1) área larga, oblíqua em sentido descendente da sutura para a margem e que se aproxima, mas não atinge a sutura; (2) faixa triangular que se inicia junto da sutura e prolonga-se obliquamente para a margem que não chega a atingir e situada perto do meio; (3) faixa transversal, mais larga junto à sutura, estreitada para o lado da margem e situada no terço apical. No macho, esta faixa é mais reduzida e a pubescência mais concentrada. Pernas pretas. Fêmures revestidos por pubescência esbranquiçada; ápices dos meso- e metafêmures com abas aguçadas. Na face ventral, pubescência branca, densa: prosterno, mesepisternos, mesosterno, região basal e lados posteriores do metasterno, metade posterior dos metepisternos, urosternitos I e II e parte central de III e IV.

Dimensões em mm, respectivamente macho/fêmea. Comprimento total, 9,8/10,6-12,7; comprimento do protórax, 2,5/2,8-3,2; maior largura do protórax, 2,4/2,7-3,2; comprimento do élitro, 6,8/7,1-8,8; largura umeral, 2,7/3,0-3,4.

Material-tipo. Holótipo fêmea, Brasil, Pará: Serra Norte (N 1. Campo), 14.VIII.1984, M. S. Torres col. (MPEG). Parátipo macho, mesma localidade (Caldeirão), 5-10.VII.1986, M. Zanuto col., armadilha malaise (MZSP). Parátipo fêmea, Brasil, Amazonas: Manaus (rodovia BR-174, km 64), 25.VIII.1985, M. Hrabovsky col. (FSCA).

Discussão. Os metafêmures ultrapassam as extremidades dos élitros o que justifica a inclusão da espécie em Neoclytus. Dentre as espécies deste gênero, Neoclytus turuna sp. nov. tem vaga semelhança com $N$. hoegei (Bate, 1970) conhecida do México e de Honduras pelo aspecto das áreas de pubescência esbranquiçada da metade basal dos élitros, mas difere pela ausência de pubescência amarelada no pronoto e pelo aspecto da faixa transversal anteapical dos élitros. Assemelha-se também a N. ictericus (Gounelle, 1911), entretanto tem os metafêmures mais curtos, não tem pubescência amarelada no pronoto e o padrão de colorido dos élitros é diferente.

\section{Neoclytus pinima sp. nov.}

(Fig. 6)

Etimologia. Tupi, pinima = pintado, alusivo ao desenho do pronoto.

Cabeça com tegumento preto, revestido por densa pilosidade amarelada, menos em área transversal, atrás dos tubérculos anteníferos, com pubescência preta. Antenas com onze artículos, apenas ultrapassam a base dos élitros. Escapo avermelhado; artículos seguintes castanho-avermelhados gradualmente mais avermelhados para o ápice. Antenômero III mais curto que o escapo. Protórax com tegumento acastanhado e, em algumas áreas, avermelhado. Pronoto (Fig. 6) revestido por pubescência amarelada, menos: (1) numa faixa 
longitudinal central, do ápice a base; (2) em duas faixas estreitas, recurvas, em "V" invertido, na metade anterior e (3) em faixa em forma de "V" na metade basal. A faixa central é granulosa e as outras têm algumas ramificações curtas.

Élitros com tegumento avermelhado; cada um com faixas estreitas de pubescência amarelada: (1) pouco mais larga que as outras, que se inicia entre o escutelo e o úmero, oblíqua em sentido descendente da base para a margem e prolongada até o quinto basal; (2) oblíqua no mesmo sentido, logo atrás do escutelo; (3) ligeiramente oblíqua em sentido descendente da sutura para a margem, que na sutura se projeta, em curta extensão, para a parte anterior e situada antes do meio; (4) transversal no terço apical. Extremidades elitrais com espículo externo. Pro- e mesofêmures cobertos, principalmente na clava, por pubescência amarelada, densa. Metafêmures pedunculados e clavados com ápices a ultrapassar as pontas dos élitros; abas apicais aguçadas. Face ventral com pubescência amarelada, densa: prosterno, mesosterno, mesepimeros, borda posterior dos mesepisternos, metasterno (menos em faixa transversal no meio), metepisternos, parte apical dos urosternitos I e II e meio do III.

Dimensões em mm, respectivamente macho/fêmea. Comprimento total, 11,6/11,7; comprimento do protórax, 2,6/ 2,6; maior largura do protórax, 2,6/2,9; comprimento do élitro, $8,2 / 8,6$; largura umeral, 3,0/3,2.

Material-tipo. Holótipo fêmea, Peru, Ica : Chanchamyo, 12.VIII.1963, Dourogeanni col. (MZSP). Parátipo macho, Bolívia, Cochabamba: Chaparé, San Jacinto $(2800$ m), III.1996, [U. Peña col.] (MZSP).

Discussão. Neoclytus pinima sp. nov. assemelha-se a $N$. aulai Bruch, 1911 pelo desenho da pubescência amarelada no pronoto. Difere pela presença de duas faixas oblíquas no quarto basal de cada élitro. Em N. aulai o pronoto tem faixas pretas, a central e duas laterais em forma de "V"; o desenho elitral é constituído por uma faixa de pubescência amarelada, oblíqua, mais larga junto à sutura.

\section{Neoclytus potiuna sp. nov.}

(Fig. 7)

Etimologia Tupi, potiá $=$ peito una $=$ preto.

Cabeça com tegumento preto menos área malar; pubescência amarela concentrada na fronte, numa faixa transversal no vértice e numa área longitudinal atrás das genas. Antenas avermelhadas com onze artículos; escapo, antenômeros III e IV com comprimentos subiguais; segmentos distais não engrossados.

Protórax globoso com tegumento preto. Pronoto com quilha longitudinal do ápice até próximo à base, encimada por grânulos; duas áreas longitudinais, de cada lado, mais discretas, também com grânulos; superfície recoberta por pubescência alaranjada.

Élitros com tegumento avermelhado e faixa longitudinal, estreita, ao longo da sutura do escutelo ao quinto apical; na base, esta faixa emite um prolongamento oblíquo para o lado da margem e que não atinge a curvatura lateral do élitro; no meio é ligeiramente alargada. Extremidades elitrais arredondadas em conjunto. Esternos torácicos com tegumento preto cobertos por pubescência amarelada. Urosternitos avermelhados. Metafêmures pedunculados e clavados, não atingem os ápices dos élitros; aba interna do ápice ligeiramente aguçada.

Dimensões em mm, holótipo fêmea. Comprimento total, 13,3; comprimento do protórax, 3,0; maior largura do protórax, 3,$4 ;$ comprimento do élitro, 8,3 ; largura umeral, 3,3 .

Material-tipo. Holótipo fêmea, Peru, Cuzco: Salinas, 15.III.1965, F. Carrasco Z. col. (MZSP).

Discussão. Neoclytus potiuna sp. nov. tem padrão de colorido elitral semelhante a $N$. suturalis Fuchs, 1963, procedente do Brasil, sem detalhes de localidade. Difere pelo tegumento avermelhado, pelo protórax sem pubescência serícea nos lados da base, pela faixa elitral muito mais estreita e sem prolongamento lateral no quinto apical, pelas extremidades elitrais arredondadas em conjunto, pelas pernas avermelhadas, pelos meso- e metafêmures com clava mais grossa. Em N. suturalis o tegumento é preto; o pronoto tem pubescência esbranquiçada nos lados da metade basal; a faixa sutural dos élitros é amarelada, mais larga e emite um prolongamento transversal para o lado da margem no quinto apical; o ápice dos élitros é transversalmente truncado e os fêmures são pretos e mais lineares.

\section{Neoclytus anama sp. nov.}

(Fig. 8)

Etimologia. Tupi, anama = parente, alusivo à semelhança com Neoclytus cacicus (Chevrolat, 1860) e N. rufus (Olivier, 1795).

Tegumento avermelhado (macho) ou acastanhado (fêmea). Cabeça revestida por pubescência amarelada, esparsa. Genas pontiagudas. Antenas com 11 artículos, atingem o terço basal (macho) ou apenas ultrapassam a base (fêmea) dos élitros. Antenômeros III e IV com comprimentos subiguais. Pronoto com pubescência amarelada, densa, junto às margens anterior e posterior nas fêmeas e só junto à margem posterior nos machos; quilha central dotada de grânulos e carínulas transversais; de cada lado do pronoto, uma elevação longitudinal com grânulos esparsos que termina numa carínula transversal à frente da orla basal. Escutelo recoberto por densa pubescência amarelo-esbranquiçada.

Élitros revestidos por pubescência avermelhada com faixas e áreas de pubescência densa amarelada: (1) faixa transversal logo atrás do escutelo; (2) essa faixa prolonga-se pela sutura até o nível do meio; (3) faixa central curva, em forma de "V" invertido com ramos bem abertos; (4) faixa no terço apical, curva em sentido inverso. Extremidades elitrais obliquamente truncadas em curva com projeção curta na lado externo. Fêmures pedunculados e clavados. Metafêmures ultrapassam 
o ápice dos élitros; extremidades com espículos curtos e subiguais. Face ventral revestida por pêlos esbranquiçados e longos. Pubescência branca, densa: mesepimeros, metade apical dos metepimeros; faixa estreita na região posterior do metasterno; faixa junto à borda apical nos urosternitos I-IV.

Dimensões em mm, respectivamente holótipo macho/ parátipo fêmea. Comprimento total, 12,5/11,2; comprimento do protórax, 3,3/3,0; maior largura do protórax, 3,2/3,1; comprimento do élitro, 8,4/7,9; largura umeral, 3,2/3,2.

Material-tipo. Holótipo macho, Equador, Loja: "mountain pass west of Loja", 8.VIII.1975, J. Longino col. (MZSP). Parátipo fêmea com os mesmos dados (MZSP).

Discussão. Neoclytus anama sp. nov. assemelha-se a $N$. cacicus (Chevrolat, 1860) e N. rufus (Olivier, 1795) e distinguese de ambas pela ausência de duas manchas muito pequenas de pubescência branca, dorsais e pouco à frente do meio dos élitros; a faixa longitudinal sutural tem lados paralelos e atinge as faixas curvas do terço anterior.

Agradecimentos. A James Wappes (ACMS, FSCA), Robert Davidson (CMNH) e William L. Overal (MPEG) pela remessa de material para estudo; a Eleandro Moyses (MCNZ) pela execução das fotografias.

\section{REFERÊNCIAS}

Bates, H. W. 1870. Contributions to an insect fauna of the Amazon Valley. The Transactions of the Entomological Society of London, 1870: 243-335; 391-444.

Bates, H. W. 1880. Biologia Centrali-Americana, Insecta, Coleoptera, Longicornes, 5: 17-152.

Monné, M. A. 2005. Catalogue of the Cerambycidae (Coleoptera) of the Neotropical Region. Part I. Subfamily Cerambycinae. Zootaxa, 946: $1-765$. 